\title{
ChemComm
}

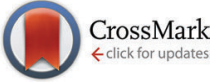

Cite this: Chem. Commun., 2016, 52,8565

Received 18th May 2016, Accepted 12th June 2016

DOI: $10.1039 / \mathrm{c} 6 \mathrm{cc0} 04202 \mathrm{c}$

www.rsc.org/chemcomm

\section{Determining carbon-carbon connectivities in natural abundance organic powders using dipolar couplings $\dagger$}

\author{
Myriam Dekhil, ${ }^{a}$ Giulia Mollica, ${ }^{a}$ Tristan Texier Bonniot, ${ }^{a}$ Fabio Ziarelli, ${ }^{b}$ \\ Pierre Thureau*a and Stéphane Viel ${ }^{a c}$
}

\begin{abstract}
We present a solid-state NMR methodology capable of investigating the carbon skeleton of natural abundance organic powders. The methodology is based on the ${ }^{13} \mathrm{C}-{ }^{13} \mathrm{C}$ dipolar coupling interaction and allows carbon-carbon connectivities to be unambiguously established for a wide range of organic solids. This methodology is particularly suitable for disordered solids, such as natural or synthetic macromolecules, which cannot be studied using conventional diffraction or NMR techniques.
\end{abstract}

Determining the connectivity between carbon atoms is the first and most important step for the structural investigation of organic molecules. In the case of organic powders that cannot be studied by conventional diffraction techniques, solid-state nuclear magnetic resonance (SSNMR) is usually regarded as a key technique. ${ }^{1-6}$ Notably, the carbon skeleton of organic powders is usually investigated using two-dimensional correlation experiments based on ${ }^{13} \mathrm{C}-{ }^{13} \mathrm{C}$ scalar $(J)$ couplings to transfer magnetisation between ${ }^{13} \mathrm{C}$ nuclei separated by a single covalent bond. Although such $J$-based experiments have been shown to produce correlations between ${ }^{13} \mathrm{C}$ that are not directly bonded (thereby potentially leading to wrong assignments), ${ }^{7}$ these experiments usually lead to the accurate determination of carbon connectivities and are particularly valuable to investigate samples isotopically enriched in ${ }^{13} \mathrm{C}$ nuclei. ${ }^{8-18}$

In the case of natural-abundance (NA) samples, however, the applicability of $J$-based experiments is often limited. In fact, because the magnetisation transfer arising from ${ }^{13} \mathrm{C}-{ }^{13} \mathrm{C}$ $J$-couplings is slow (with respect to the decay of the ${ }^{13} \mathrm{C}$ transverse magnetisation), it is typically barely detectable for NA samples. As a result, establishing carbon-carbon connectivities in NA samples using $J$-based experiments usually requires

\footnotetext{
${ }^{a}$ Aix-Marseille Université, CNRS, ICR (UMR 7273), 13397 Marseille, France. E-mail: pierre.thureau@univ-amu.fr; Tel: +33 (0)491 288578

${ }^{b}$ Aix-Marseille Université, Centrale Marseille, CNRS, Fédération des Sciences Chimiques de Marseille (FR 1739), 13397 Marseille, France

${ }^{c}$ Institut Universitaire de France, 75005 Paris, France

$\dagger$ Electronic supplementary information (ESI) available: Predicted signal intensities, experimental recoupling efficiencies, experimental details. See DOI: 10.1039/c6cc04202c
}

extensively long experimental times in the case of crystalline or semi-crystalline samples ${ }^{19-28}$ (approximately a week) and is seldom practicable in the case of NA disordered solids that display broad ${ }^{13} \mathrm{C}$ NMR linewidths arising from fast ${ }^{13} \mathrm{C}$ transverse magnetisation decay. ${ }^{29,30}$

Herein, we demonstrate that an unambiguous assignment of carbon connectivities in NA organic powders, especially disordered solids, can be obtained from 2D correlation experiments that are based on ${ }^{13} \mathrm{C}^{13} \mathrm{C}$ dipolar couplings. ${ }^{30,31} \mathrm{An}$ important feature of dipolar-based experiments is that the magnetisation transfer builds up much faster than in $J$-based experiments, and hence dipolar-based experiments are suitable for organic solids with fast ${ }^{13} \mathrm{C}$ transverse magnetisation decays. Moreover, we show here that a magnetisation transfer time of $0.4 \mathrm{~ms}$ leads exclusively to correlation signals between covalently bonded ${ }^{13} \mathrm{C}-{ }^{13} \mathrm{C}$ pairs. In contrast, signals arising from ${ }^{13} \mathrm{C}^{13} \mathrm{C}$ pairs separated by more than one covalent bond are at least 5 times weaker, and thus would not be detected in $2 \mathrm{D}^{13} \mathrm{C}-{ }^{13} \mathrm{C}$ DQ dipolar correlation spectra of NA samples (ESI $\dagger$ ).

Fig. 1 shows the pulse sequence for magic-angle spinning (MAS) 2D dipolar-based ${ }^{13} \mathrm{C}^{13} \mathrm{C}$ correlation experiments. The recoupling of the ${ }^{13} \mathrm{C}^{13} \mathrm{C}$ dipolar interaction is based on the $R 20_{2}^{9}$ symmetry, ${ }^{32-34}$ which generates during the first delay $\tau_{\mathrm{DQ}}$ double quantum (DQ) coherences that subsequently evolve during $t_{1}$ at the sum of the chemical shift frequencies of pairs of coupled ${ }^{13} \mathrm{C}^{13} \mathrm{C}$ nuclei, before being reconverted during the second $\tau_{\mathrm{DQ}}$ into single quantum coherences for detection during $t_{2}$. It should be noted that, for NA samples, DQ coherences are useful not only for straightforward data interpretation but also to suppress intense signals arising from the large number of uncoupled ${ }^{13} \mathrm{C}$ nuclei.

Interestingly, the $R 20_{2}^{9}$ symmetry is particularly robust with respect to ${ }^{1} \mathrm{H}^{13} \mathrm{C}$ dipolar coupling and ${ }^{13} \mathrm{C}$ chemical shift anisotropy (CSA). ${ }^{32,35-37}$ Notably, no ${ }^{1} \mathrm{H}$ decoupling is required during the ${ }^{13} \mathrm{C}$ recoupling periods $\tau_{\mathrm{DQ}}{ }^{32-34}$ and, thus, this experiment is very easy to implement (only the ${ }^{13} \mathrm{C} 90^{\circ}$ pulse needs to be calibrated). It should be noted that the $R 20_{2}^{9}$ symmetry is appropriate for a MAS frequency of $10 \mathrm{kHz}$. 
a)

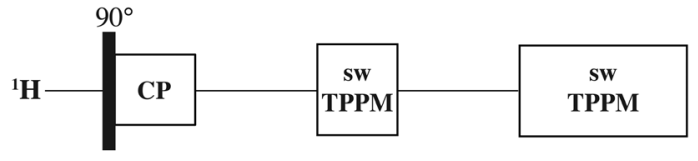

b)

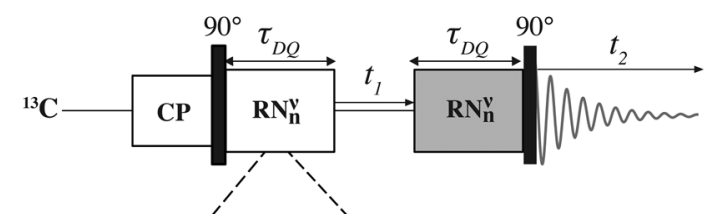

c)

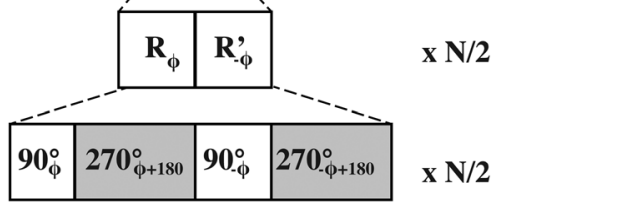

Fig. 1 Pulse sequence for $2 \mathrm{D}^{13} \mathrm{C}-{ }^{13} \mathrm{C}$ correlation experiments based on dipolar coupling (a). The $R N_{n}^{\nu}$ symmetry was applied during the delays $\tau_{\mathrm{DQ}}$ to excite and reconvert double quantum (DQ) coherences, yielding correlation peaks in the indirect dimension of the $2 \mathrm{D}$ spectrum at the sum of the chemical shifts of the 2 coupled ${ }^{13} \mathrm{C}$ nuclei. The selected symmetry ( $N=20, n=2$ and $\nu=9$ ) led to $10 R_{\phi}, R_{-\phi}{ }^{\prime}$ elements fitting into 2 rotor periods, with $\phi=81^{\circ}$ (b). The basic element is shown in (c) and it consists of a composite $180^{\circ}$ pulse.

In this case, a $4 \mathrm{~mm}$ MAS rotor can be used, providing the best compromise between MAS frequency and sensitivity for NA samples at $9.4 \mathrm{~T}$.

Furthermore, using our instrumentation, the DQ recoupling of the ${ }^{13} \mathrm{C}-{ }^{13} \mathrm{C}$ dipolar interaction using the $R 20_{2}^{9}$ symmetry is 1.7 times more efficient than standard dipolar recoupling symmetries, such as POST-C $7^{38}$ or SPC $^{39}$ (see the ESI $\dagger$ ). This enhancement translates in substantial shorter experimental times, i.e. 2.9 times faster, and as a result, $2 \mathrm{D}^{13} \mathrm{C}-{ }^{13} \mathrm{C}$ correlation experiments for NA samples can be obtained within practicable experimental durations using standard solid-state NMR hardware at room temperature.

The 2D dipolar-based ${ }^{13} \mathrm{C}-{ }^{13} \mathrm{C}$ correlation spectrum for a powder sample of L-tyrosine ethyl ester is shown in Fig. 2. The 2D spectrum was recorded using a $9.4 \mathrm{~T}$ magnet and a MAS frequency of $10 \mathrm{kHz}$; the experimental time was 3 days. The 1D ${ }^{13} \mathrm{C}$ cross-polarisation (CP) MAS spectrum is also shown above the $2 \mathrm{D}$ spectrum. Remarkably, the resonances corresponding to aromatic carbons are significantly broader than the other ${ }^{13} \mathrm{C}$ signals. This broadening results from the fast ${ }^{13} \mathrm{C}$ transverse magnetisation decay arising from molecular motion. ${ }^{40,41}$ As a result, correlation signals involving the aromatic carbons are not detectable using $J$-based correlation experiments. ${ }^{22}$ In contrast, all the ${ }^{13} \mathrm{C}-{ }^{13} \mathrm{C}$ correlation signals between covalently bonded ${ }^{13} \mathrm{C}$ nuclei are observed in the $2 \mathrm{D}$ dipolar-based ${ }^{13} \mathrm{C}-{ }^{13} \mathrm{C}$ correlation spectrum with excellent resolution and sensitivity.

Fig. 3 illustrates the capabilities of $2 \mathrm{D}$ dipolar-based ${ }^{13} \mathrm{C}-{ }^{13} \mathrm{C}$ correlation experiments to investigate a disordered solid, here, an amorphous poly(methyl methacrylate) (PMMA) sample. This spectrum has been recorded in less than 2 days. Interestingly, the ${ }^{13} \mathrm{C}$ signals of PMMA arise from both mobile and rigid ${ }^{13} \mathrm{C}$ sites. For example, the $\mathrm{OCH}_{3}$ or $\mathrm{CO}$ resonances correspond to the mobile part of PMMA while the $\mathrm{CH}_{2}$ or $\mathrm{CH}_{3}$ resonances

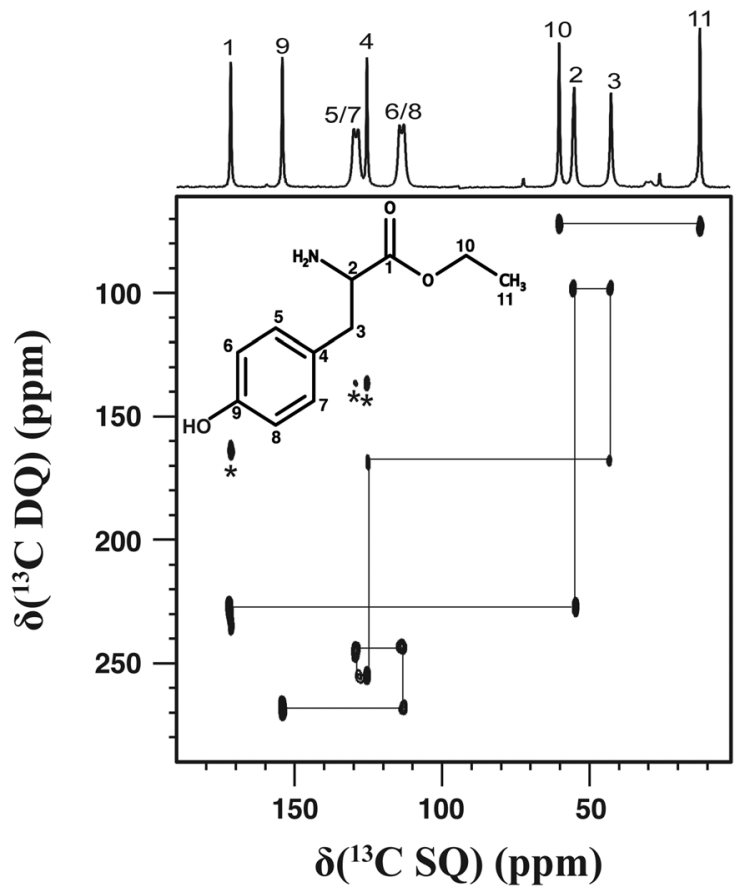

Fig. $2{ }^{13} \mathrm{C}-{ }^{13} \mathrm{C} D Q$ dipolar correlation spectrum of L-tyrosine ethyl ester powder. The spectrum was recorded using $\tau_{\mathrm{DQ}}=0.4 \mathrm{~ms}$, a MAS frequency of $10 \mathrm{kHz}, 27 t_{1}$ increments and 1600 repetitions for each $t_{1}$ increment. The repetition delay was $3 \mathrm{~s}$. The total experimental time was 3 days. The ${ }^{13} \mathrm{C}$ CPMAS spectrum is shown in the top projection. The symbol $\left(^{*}\right)$ indicates spinning sidebands.

correspond to the more rigid backbone chain. ${ }^{42}$ We notice in Fig. 3 that, notwithstanding significant mobility differences, all the correlation peaks arising from covalently bonded ${ }^{13} \mathrm{C}-{ }^{13} \mathrm{C}$ pairs could be observed in the $2 \mathrm{D}^{13} \mathrm{C}-{ }^{13} \mathrm{C}$ DQ dipolar correlation spectrum. $\$$ We emphasise that $2 \mathrm{D}$ dipolar-based ${ }^{13} \mathrm{C}-{ }^{13} \mathrm{C}$ correlation experiments are suitable to samples that give rise to observable signals in ${ }^{13} \mathrm{C}$ CPMAS experiments. In the case of samples with high molecular mobility, which are intrinsically unsuitable for ${ }^{13} \mathrm{C}$ CPMAS experiments, ${ }^{43}$ it would be more advantageous to directly excite ${ }^{13} \mathrm{C}$ nuclei and to explore ${ }^{13} \mathrm{C}-{ }^{13} \mathrm{C}$ connectivities through $J$-based experiments. ${ }^{30}$ Nevertheless, we have shown here (Fig. 2 and 3) that 2D dipolar-based ${ }^{13} \mathrm{C}-{ }^{13} \mathrm{C}$ correlation experiments are useful even for solids subjected to molecular motions.

An additional example is shown in Fig. 4 for cellulose, a natural polymer containing both amorphous and crystalline phases. The $1 \mathrm{D}{ }^{13} \mathrm{C}$ CPMAS spectrum is shown above the $2 \mathrm{D}$ ${ }^{13} \mathrm{C}-{ }^{13} \mathrm{C}$ DQ dipolar correlation spectrum. In the $1 \mathrm{D}{ }^{13} \mathrm{C}$ CPMAS spectrum the apparent line widths range from 400 to $600 \mathrm{~Hz}$ and are partly related to the disordered character of the sample. The $2 \mathrm{D}{ }^{13} \mathrm{C}-{ }^{13} \mathrm{C}$ DQ dipolar correlation spectrum was recorded within 3 days and all one-bond correlations were observed with very good sensitivity and satisfactory resolution. Notably, the assignment based on dipolar coupling experiments is in agreement with the assignment based on $J$-coupling experiments. $\S^{29}$ Moreover, correlation peaks corresponding to both amorphous and crystalline signals are observed in the $2 \mathrm{D}{ }^{13} \mathrm{C}-{ }^{13} \mathrm{C}$ 


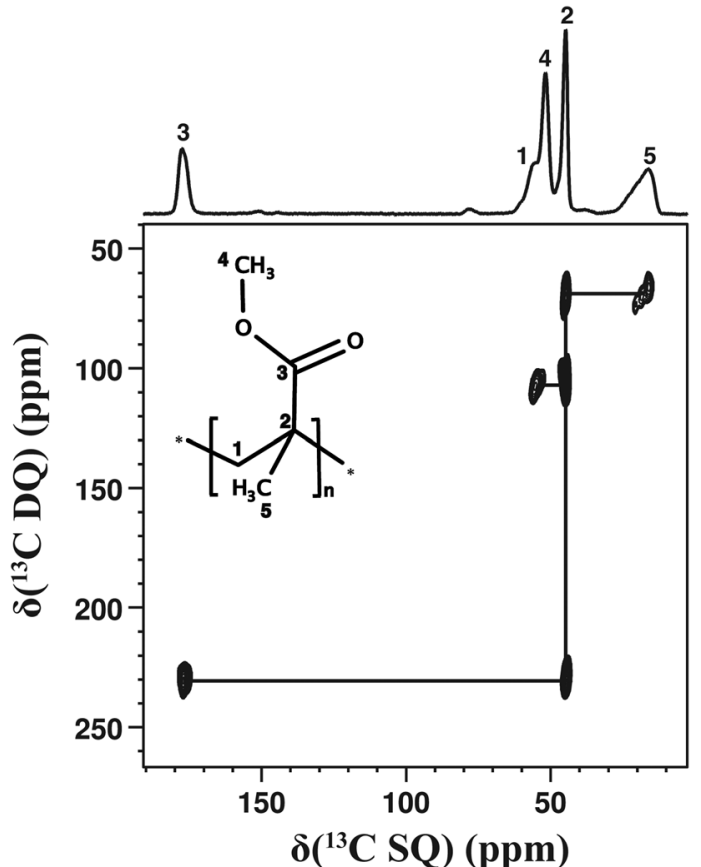

Fig. $3{ }^{13} \mathrm{C}-{ }^{13} \mathrm{C} D Q$ dipolar correlation spectrum of a synthetic polymer, the poly (methyl methacrylate) (PMMA), recorded with $\tau_{\mathrm{DQ}}=0.4 \mathrm{~ms}$, a MAS frequency of $10 \mathrm{kHz}, 38 t_{1}$ increments and 1024 repetitions for each $t_{1}$ increment. The repetition delay was set to $2 \mathrm{~s}$. The total experimental time was 1.8 days. The ${ }^{13} \mathrm{C}$ CPMAS spectrum is shown in the top projection.

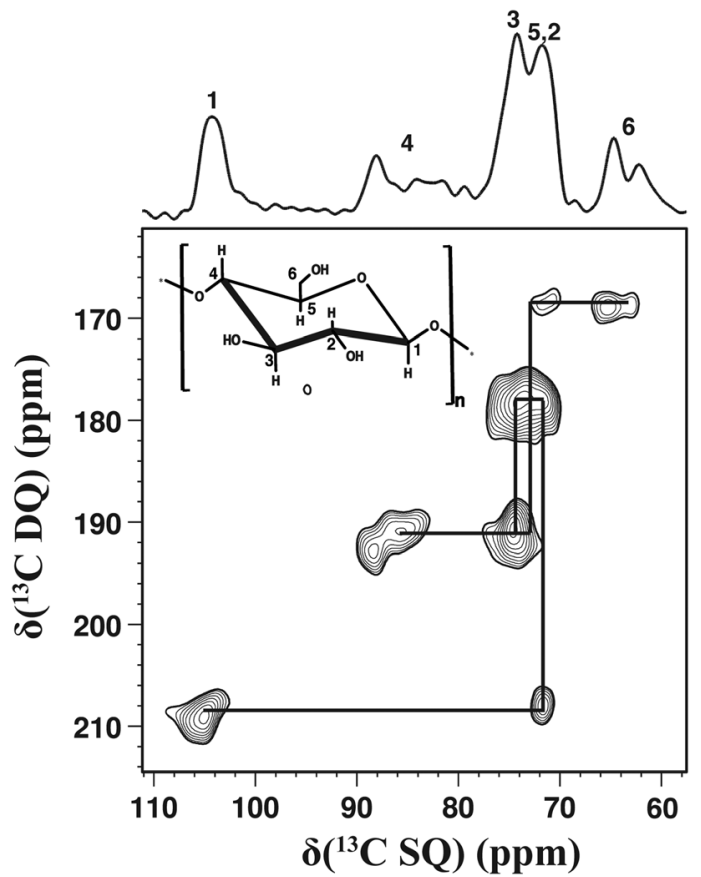

Fig. $4{ }^{13} \mathrm{C}-{ }^{13} \mathrm{C}$ DQ dipolar correlation spectrum of cellulose, recorded with $\tau_{\mathrm{DQ}}=0.4 \mathrm{~ms}$, a MAS frequency of $10 \mathrm{kHz}, 20 \mathrm{t}_{1}$ increments and 2048 repetitions for each $t_{1}$ increment. The repetition delay was $3.2 \mathrm{~s}$. The total experimental time was approximately 3 days. The ${ }^{13} \mathrm{C}$ CPMAS spectrum is shown in the top projection.

DQ dipolar correlation spectrum, as exemplified for the signals at $86 \mathrm{ppm}$ and $63 \mathrm{ppm}$.
In summary, we have shown that unambiguous carboncarbon connectivities in NA organic solids can be determined using dipolar-based ${ }^{13} \mathrm{C}-{ }^{13} \mathrm{C}$ correlation experiments. These experiments can be performed within practicable experimental times and are suitable for different kinds of samples, such as molecular crystals and disordered solids including synthetic or natural polymers. This methodology is complementary to $J$-based ${ }^{13} \mathrm{C}-{ }^{13} \mathrm{C}$ correlation experiments, especially in the case of NA disordered solids having fast ${ }^{13} \mathrm{C}$ transverse magnetisation decay. Finally, the methodology presented here can be carried out at room temperature and is thus complementary to ${ }^{13} \mathrm{C}-{ }^{13} \mathrm{C}$ correlation experiments enhanced with dynamic nuclear polarisation, ${ }^{44-47}$ which require samples that can be analysed at cryogenic temperatures and in the presence of paramagnetic dopants.

This work has been carried out thanks to the support from the French National Research Agency (ANR) grant number ANR-13-JS080001.

\section{References}

$\ddagger$ Molecular mobility could potentially reduce the DQ correlation intensity as a result of partial averaging of the ${ }^{13} \mathrm{C}-{ }^{13} \mathrm{C}$ DQ dipolar coupling.

$\S J$-coupling experiments were recorded on a partially ${ }^{13} \mathrm{C}$ enriched cellulose sample.

1 D. Massiot, R. J. Messinger, S. Cadars, M. Deschamps, V. Montouillout, N. Pellerin, E. Veron, M. Allix, P. Florian and F. Fayon, Acc. Chem. Res., 2013, 46, 1975-1984.

2 R. J. Messinger, K. Na, Y. Seo, R. Ryoo and B. F. Chmelka, Angew. Chem., Int. Ed., 2015, 54, 927-931.

3 M. R. Hansen, R. Graf and H. W. Spiess, Chem. Rev., 2016, 116, 1272-1308.

4 S. Radhakrishnan, P.-J. Goossens, P. C. M. M. Magusin, S. P. Sree, C. Detavernier, E. Breynaert, C. Martineau, F. Taulelle and J. A. Martens, J. Am. Chem. Soc., 2016, 138, 2802-2808.

5 C. M. Widdifield, H. Robson and P. Hodgkinson, Chem. Commun., 2016, 52, 6685-6688.

6 S. E. Ashbrook and D. McKay, Chem. Commun., 2016, 52, 7186-7204.

7 F. Fayon, D. Massiot, M. H. Levitt, J. J. Titman, D. H. Gregory, L. Duma, L. Emsley and S. P. Brown, J. Chem. Phys., 2005, 122, 194313.

8 G. Grasso, T. M. de Swiet and J. J. Titman, J. Phys. Chem. B, 2002, 106, 8676-8680.

9 G. De Paepe, N. Giraud, A. Lesage, P. Hodgkinson, A. Böckmann and L. Emsley, J. Am. Chem. Soc., 2003, 125, 13938-13939.

10 E. H. Hardy, A. Detken and B. H. Meier, J. Magn. Reson., 2003, 165, 208-218.

11 S. Cadars, A. Lesage and L. Emsley, J. Am. Chem. Soc., 2005, 127, 4466-4476.

12 L. Chen, R. A. Olsen, D. W. Elliott, J. M. Boettcher, D. H. Zhou, C. M. Rienstra and L. J. Mueller, J. Am. Chem. Soc., 2006, 128, 9992-9993.

13 F. Fayon, C. Roiland, L. Emsley and D. Massiot, J. Magn. Reson., 2006, 179, 49-57.

14 R. Witter, U. Sternberg, S. Hesse, T. Kondo, F.-T. Koch and A. S. Ulrich, Macromolecules, 2006, 39, 6125-6132.

15 L. Chen, J. M. Kaiser, T. Polenova, J. Yang, C. M. Rienstra and L. J. Mueller, J. Am. Chem. Soc., 2007, 129, 10650-10651.

16 N. Baccile, G. Laurent, F. Babonneau, F. Fayon, M.-M. Titirici and M. Antonietti, J. Phys. Chem. C, 2009, 113, 9644-9654.

17 D. Lee, J. Struppe, D. W. Elliott, L. J. Mueller and J. J. Titman, Phys. Chem. Chem. Phys., 2009, 11, 3547-3553.

18 X. Liu, W. Chen, Y. lee Hong, S. Yuan, S. Kuroki and T. Miyoshi, Macromolecules, 2015, 48, 5300-5309.

19 A. Lesage, C. Auger, S. Caldarelli and L. Emsley, J. Am. Chem. Soc., 1997, 119, 7867-7868.

20 R. A. Olsen, J. Struppe, D. W. Elliott, R. J. Thomas and L. J. Mueller, J. Am. Chem. Soc., 2003, 125, 11784-11785. 
21 H. Kono, T. Erata and M. Takai, Macromolecules, 2003, 36, 5131-5138.

22 G. De Paëpe, A. Lesage, S. Steuernagel and L. Emsley, ChemPhysChem, 2004, 5, 869-875.

23 H. Kono, Biopolymers, 2004, 75, 255-263.

24 J. Brus and A. Jegorov, J. Phys. Chem. A, 2004, 108, 3955-3964.

25 R. K. Harris, S. A. Joyce, C. J. Pickard, S. Cadars and L. Emsley, Phys. Chem. Chem. Phys., 2006, 8, 137-143.

26 R. K. Harris, S. Cadars, L. Emsley, J. R. Yates, C. J. Pickard, R. K. R. Jetti and U. J. Griesser, Phys. Chem. Chem. Phys., 2007, 9, 360-368.

27 M. Deschamps, S. Cadars, E. Gilbert, P. Azas, E. Raymundo-Pinero, F. Béguin and D. Massiot, Solid State Nucl. Magn. Reson., 2012, 42, 81-86.

28 M. Baias, J.-N. Dumez, P. H. Svensson, S. Schantz, G. M. Day and L. Emsley, J. Am. Chem. Soc., 2013, 135, 17501-17507.

29 A. Lesage, M. Bardet and L. Emsley, J. Am. Chem. Soc., 1999, 121, 10987-10993.

30 Y. Su and M. Hong, J. Phys. Chem. B, 2011, 115, 10758-10767.

31 M. Hong, J. Magn. Reson., 1999, 136, 86-91.

32 M. Carravetta, M. Eden, O. G. Johannessen, H. Luthman, P. J. E. Verdegem, J. Lugtenburg, A. Sebald and M. H. Levitt, J. Am. Chem. Soc., 2001, 123, 10628-10638.

33 M. H. Levitt, in Encyclopedia of Nuclear Magnetic Resonance, ed. D. M. Grant and R. Harris, John Wiley \& Sons, Ltd, Chichester, 2002, vol. 9, p. 165.

34 M. Eden, eMagRes, John Wiley \& Sons, Ltd, 2013, vol. 2, pp. 351-364.
35 C. E. Hughes, S. Luca and M. Baldus, Chem. Phys. Lett., 2004, 385, 435-440.

36 I. Marin-Montesinos, D. H. Brouwer, G. Antonioli, W. C. Lai, A. Brinkmann and M. H. Levitt, J. Magn. Reson., 2005, 177, 307-317.

37 O. Lafon, J. Trebosc, B. Hu, G. De Paepe and J.-P. Amoureux, Chem. Commun., 2011, 47, 6930-6932.

38 M. Hohwy, H. J. Jakobsen, M. Edén, M. H. Levitt and N. C. Nielsen, J. Chem. Phys., 1998, 108, 2686.

39 M. Hohwy, C. M. Rienstra, C. P. Jaroniec and R. G. Griffin, J. Chem. Phys., 1999, 110, 7983.

40 L. Frydman, S. Vallabhaneni, Y. K. Lee and L. Emsley, J. Chem. Phys., 1994, 101, 111-117.

41 X. Helluy and A. Sebald, J. Phys. Chem. B, 2003, 107, 3290-3296.

42 E. R. deAzevedo, W.-G. Hu, T. J. Bonagamba and K. Schmidt-Rohr, J. Am. Chem. Soc., 1999, 121, 8411-8412.

43 R. Zhang, K. H. Mroue and A. Ramamoorthy, J. Magn. Reson., 2016, 266, 59-66.

44 A. J. Rossini, A. Zagdoun, F. Hegner, M. Schwarzwälder, D. Gajan, C. Copéret, A. Lesage and L. Emsley, J. Am. Chem. Soc., 2012, 134, 16899-16908.

45 H. Takahashi, D. Lee, L. Dubois, M. Bardet, S. Hediger and G. De Paepe, Angew. Chem., Int. Ed., 2012, 51, 11766-11769.

46 G. Mollica, M. Dekhil, F. Ziarelli, P. Thureau and S. Viel, Angew. Chem., Int. Ed., 2015, 54, 6028-6031.

47 R. L. Johnson, F. A. Perras, T. Kobayashi, T. J. Schwartz, J. A. Dumesic, B. H. Shanks and M. Pruski, Chem. Commun., 2016, 52, 1859-1862. 